\title{
Intensity and Determinants of Rural Poverty in Banja District of Awi Zone, Amhara National Regional State, Ethiopia
}

\author{
Desalegn Teshale Woldie ${ }^{1, ~ *}$, Jema Haji ${ }^{2}$, Abule Mehare ${ }^{2}$ \\ ${ }^{1}$ Agricultural Economics Research Directorate, Ethiopian Institute of Agricultural Research (EIAR), Pawe Research Centre, Pawe, Ethiopia \\ ${ }^{2}$ School of Agricultural Economics \& Agri-business Management, Haramaya University, Haramaya, Ethiopia
}

Email address:

desiteshale@gmail.com (D. T. Woldie),jemmahaji@gmail.com (J. Haji), abule.mehare@gmail.com (A. Mehare)

${ }^{*}$ Corresponding author

\section{To cite this article:}

Desalegn Teshale Woldie, Jema Haji, Abule Mehare. Intensity and Determinants of Rural Poverty in Banja District of Awi Zone, Amhara National Regional State, Ethiopia. International Journal of Agricultural Economics. Special Issue: Agricultural Economics and Its Related. Vol. 5, No. 3, 2020, pp. 49-62. doi: 10.11648/j.ijae.20200503.11

Received: March 25, 2020; Accepted: May 11, 2020; Published: May 29, 2020

\begin{abstract}
Poverty is one of the most serious problems of human deprivation and a complex phenomenon. Ethiopian government have been implementing different poverty reduction programs and strategies to fight extreme hunger and poverty. The struggle to reduce rural poverty at household level is a continuing challenge. This study was conducted in Banja district of Awi zone Amhara regional state. The specific objectives of this study were to estimate the rural poverty status, to identify factors determining rural poverty and to estimate the average exit time of poor households. In order to achieve these objectives, cross sectional data on human capital, physical capital, financial capital, natural capital and other institutional characteristics were collected from 190 households drawn from randomly selected five kebeles using structured household questioner. Descriptive and inferential statistics, and econometric model were used to analyze data on poverty status and poverty level, respectively. Hence, setting the poverty line, identifying poor and non-poor rural households, measuring the incidence, depth and severity, and mean comparison between the groups were made. Accordingly, using Cost of Basic Needs approach, the estimated poverty line was Birr 4301 per adult equivalent per year. The Foster Greer and Thorbeck measure of poverty found that 44 percent of sample households were found below poverty line and the poverty gap and poverty severity were 9 percent and 2 percent, respectively. The estimated average exit time of the poor households based on the five-year average per capita Gross Domestic Product growth rate was 3.35 years. Tobit model result showed that household size significantly and positively influence poverty whereas number of livestock and oxen ownership, educational level of the household head, input utilization, asset ownership and credit utilization negatively influenced poverty in the study area. The result suggests that improving adult education, provision of input for smallholder farmers, improving access and availability of credit, improving the livestock sector will be important policy interventions.
\end{abstract}

Keywords: Rural Poverty, Banja, Determinant, Tobit

\section{Introduction}

Poverty is one of the most serious problems of human deprivation and a complex phenomenon. It is a multidimensional concept which encompasses inadequate income and short of the necessities such as education, health services, clean water and hygiene which are crucial elements for human dignity and survival. Therefore, dealing with poverty is a priority development concern in many developing countries in general and sub-Saharan countries in particular [1].

Poverty is a threat to the world, especially in developing countries. The governments, national and international development institutions have tried to understand the nature of poverty and mechanisms of reducing it. Development economists argued that the fight against poverty is necessary condition for any economic growth thereby achieve the wellbeing of citizens. 
Although the proportion of households living in poverty and extreme poverty in developing countries have been declining over the past three decades, the numbers remain high, with almost one billion people considered to be extremely poor and another one billion are poor. Notably, Extreme poverty has fallen substantially in East Asia and the Pacific as well as in South Asia. However, in sub-Saharan Africa, little progress has been made and almost half the population is extremely poor [2]. Hence, the highest regional poverty rate is in Sub-Saharan Africa, where 42.7 percent of the population is estimated to be below the global poverty line, followed by South Asia (18.8 percent) and East Asia (7.2 percent) [3]. That's why any country in these regions consider poverty reduction programs as the prime objective of their national development plan. This was witnessed by world leaders by setting the Millennium Development Goal on Eradicating extreme poverty and hunger by 2015 .

Nearly, three-fourth of the poor in the developing world lives in rural areas, and rural poverty remains high and persistent. Majority of sub-Saharan African population, 63 percent, lives in rural areas where their daily income is less than US\$ 1.90 a day. Overall, the rural population is hit much harder by poverty than people living in urban areas. Even though rapid economic growth and quick poverty reduction are witnessed in East Asia, sluggish and deteriorating growth in Sub Saharan countries is not quick enough to reduce extreme poverty [4].

Majority of people in Ethiopia, by any standard, are among the poorest in the world [5]. It is a common and widespread phenomenon in which a larger proportion of its population lives below one US dollar a day. Based on the Human Development Index (HDI), Ethiopia is classified as a low human development implying that many of its citizens are seriously deprived of basic needs like food, shelter, education and health. The HDI for 2015 was 0.448 which is below the average of sub-Saharan African countries (0.523) and put a country on a rank of 174 out of 187 countries. The figure clearly indicates that Ethiopia is one of the poorest nations in the world [6].

Realizing the worst situation of poverty in the country, the government of Ethiopia has implementing different poverty reduction strategies in order to make the country among one of the middle-income countries by 2025. Notably, Sustainable Development and Poverty reduction program, Plan for Accelerated and Sustained Development to End Poverty, Growth and Transformational Plan I and most recently phase two of GTP have been implemented to reduce the extreme poverty. Following these major national programs and strategies, the country has registered a promising economic growth that helps a significant proportion of people move out of the poverty trap. According to UNDP report [6] report, the Ethiopian GDP per capita for the year 2015 was $\$ 1,530$ US dollar (at $2011 \mathrm{PPP}$ ). The real Gross Domestic Product growth rate for the same year was 8.7 percent.

This study was conducted in Banja District of Awi zone, where mixed farming system is the main livelihood of the rural farmers. The rural poverty scenario in the study district requires depth analysis in that the situation of rural poverty might be more chronic than other areas in the region. Besides, those who are assumed non-poor now, may inevitably be vulnerable to poverty in the coming years. Therefore, identifying and analyzing the poverty measures and determinant factors of the poverty level in the study area is crucial. Besides, it could help to close the information and knowledge gaps that are hindering in addressing the poor households through implementation of area specific development interventions and strategies. Hence, this study could have paramount importance in the study area in particular and the region in general.

\subsection{Statement of the Problem}

In much of sub-Saharan Africa countries, agriculture is the mainstay of economic growth, overcoming poverty, and enhancing food security. Of the total population of SSA in 2003, 66 percent lived in rural areas and more than 90 percent of people in these regions depended on agriculture for their livelihoods [7]. Nearly, 70 percent of the population in the world who are below the poverty line are located in Sub Saharan African countries [8]. Hence, improving rural areas means improving the lives of the most chronically poor people. Thus, the agricultural sector will have paramount importance to lift millions of people out of poverty.

Ethiopia, like the other Sub-Saharan African country, is still suffering from widespread and severe poverty. Since 80 percent of the Ethiopian economy is based on the agricultural sector, the country's national policies and strategies are targeted to reduce poverty through increasing the productivity of this sector. The programs provided credit, agricultural input, access to better extension packages, expansion of rural infrastructural services mainly irrigation canals, rural road construction, health services, telecommunication services, and primary education.

In mid-1990's, Ethiopia was one of the highest poverty rates in the world, with 55.3 percent of the population living on less than the global poverty line (US $\$ 1.25$ per day) and 45.5 percent of its population live below the national poverty line. By 2011, 33.5 and 29.6 percent of the populations lived on less than the global and national poverty line respectively [9] (World Bank, 2016). Thus, a country had achieved substantial progress in reducing extreme poverty in the last twenty years.

Even though various poverty reduction policies and strategies have been implemented and, hence rapid economic growth in the past decade was registered, a significant proportion of the population still live in absolute poverty situation. For instance, in the years 2014/15, the Ethiopian economy registered the real gross domestic product (GDP) of 8.7 percent which was better than sub-Saharan countries [10]. But this economic growth was not enough to eradicate extreme poverty in the country particularly rural areas.

Following different reforms and poverty reduction strategies that have been implemented in the country, there could have been a reduction of poverty both at the national 
and regional levels. For instance, in 2015/16 the national poverty level was 23.5 percent. Across regions, the analysis of HICE survey result of 2015/16, Amhara region experienced headcount index of 26.1 percent which is higher than the national average. Moreover, rural and urban poverty headcount index in the region stood at 28.8 percent and 11.6 percent, respectively in which the former is above the national rural headcount index of 25.6 percent. This implies that rural poverty is a widespread problem in the region in particular and the country as a whole.

Banja district is one of the nine administrative districts in Awi Zone. According to agricultural offices of the district, it is characterized by high population, low agricultural productivity, the high number of migrants to urban centers, poor rural infrastructure and weak institutional support service. Accordingly, the district is identified as one of the poorest districts in Awi Zone. Following this, efforts have been made to improve the livelihood of farmers. By increasing the speed of the growth of the agricultural sector, the living standard of the rural farmers can be improved. However, this is not the reality in Banja district. Based on the information obtained from the agricultural office of Banja district, substantial number of poor farmers are selling or renting their natural asset like land and move out of their village in search of food to his/her family to urban areas at least temporarily. Besides, family dissolving is getting common phenomenon in the study area. Moreover, production and productivity of farm households are getting worse due to the acidic nature of the soil. Thus, rural farmers in Banja district are hardly breaking the vicious circle of poverty.

Therefore, to fight against poverty in rural areas of the study district and reverse the situation at the minimum possible level, it requires depth understanding and need to design pro-poor and location or district-specific poverty reduction policies and strategies. Hence, critical assessment of rural poverty in the district helps to identify who the poor are and why they are being poor and getting poor, what contributes them to be poor and what poverty reduction intervention or strategy might be appropriate.

Moreover, poverty analysis carried out elsewhere might not be applicable in the other areas due to differences in socio-cultural, economic, geographic zones and differences in livelihood strategies. Thus, critical analysis of rural poverty at the district level is important.

To the best of the researcher, studies with special focus on poverty analysis and factors affecting rural poverty are not yet studied in Banja district. Hence, this study is assumed to fill the existing knowledge gap concerning the magnitude, extent and scenario of poverty and to suggest appropriate policy intervention options aimed at reducing and eradicating rural poverty.

\subsection{Research Questions}

The underlining research questions of this study were:

1. What is the magnitude, extent and status of poverty in rural part of Banja district?
2. How long would it take for the poor rural household to exit poverty if GDP per capita of the country grows at a positive rate per year?

3. What are the major determinant factors of rural poverty in the study area?

4. What is the level or intensity of poverty in the study area?

\subsection{Objectives of the Study}

The general objective of the study was to assess rural poverty situation in Banja District of Amhara National Regional State. The study had the following specific objectives;

1. To examine the extent, depth and severity of household's poverty in rural areas of Banja district;

2. To estimate the average time required to exit the poverty of rural poor households, and

3. To analyze the determinants of rural household poverty in the study area

\section{Research Methodology}

\subsection{Description of the Study Area}

This study was conducted in Banja district of Awi zone in Amhara National Regional State of Ethiopia. The district is bordered on the south by Ankesha, on the West by Guangua, on the North by Fageta Lekoma and in the East by the West Gojam zone. The district is consisting of 26 kebeles of which 25 are rural kebeles and one urban kebele. Injibara town is both the capital of Awi zone and Banja district. The town is located about $450 \mathrm{kms}$ North West of Addis Ababa and 118 Km South of Bahir Dar.

Total population of the district was 111,975 out of this 56,364 (50.3 percent) were female and 55,6115 (49.6 percent) were male [11]. The number of farm households were 16,239 out of this 13,684 were male headed households and 2,555 were female headed households. The district has the total area of 47,915.82 ha. Land use pattern of the district is 12,277 ha cultivated land, 21,141.57 ha grazing/pasture land, 12,346 ha covered by forest and the rest 2,151.24 ha for other uses. The district comprised of Dega ( 80 percent) and Winadega (20 percent) agro ecologies and the altitude ranges from 1900- 2750 meter above sea level. The annual temperature is $26^{\circ} \mathrm{C}$ at the maximum and $16^{\circ} \mathrm{C}$ at minimum. It has unimodal rainfall distribution pattern. The rainy season for the area starts in May and extends to the end of October. The average annual rainfall reaches $2300 \mathrm{~mm}$. Crop production, livestock farming and forestry are the main sources of livelihood of farmers in the district [12].

Crop production: The farming system of the district is mainly characterized by mixed farming where crop and livestock production are undertaken as it is the major livelihood strategies of the rural poor in the district. Major crops produced in the district are, potato, teff, maize, wheat, barley, finger millet and other crops like bean and onion The major crops area coverage produced in the district in 2017/18 
cropping calendar was potato, teff, wheat and maize which covers 3200, 2800, 2000 and 1350 hectares, respectively. Some farm households use irrigation, particularly for potato and onion production which is the main crops produced and traded in the district [12].

Livestock production: Livestock in the study area includes cattle, shoats, equine and poultry. The population of the livestock sector in $2017 / 18$ production year were 74,379 TLU. The livestock sector contributes to crop production as draught power, source of cash income, manure, transport services and cultural services. By selling livestock and livestock products rural communities in the district tried to subsidize their consumption. Horses are the main source of draught power in the study area.

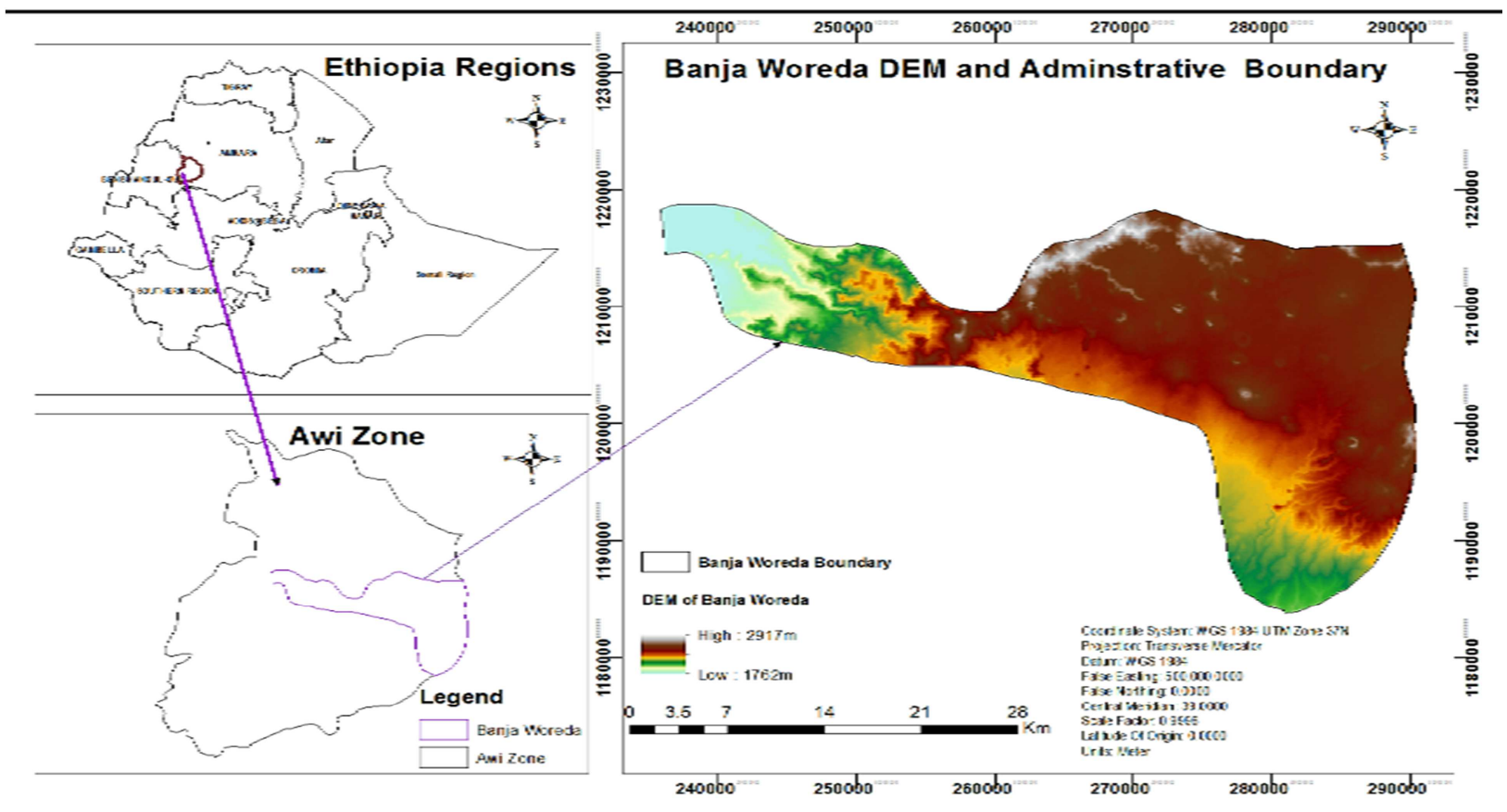

Source: Ethiopian Map Agency (2018)

Figure 1. Location of the study area.

\subsection{Sampling Technique and Sample Size}

Both primary and secondary data sources were used to collect quantitative and qualitative data. Primary data on demographic characteristics, socioeconomic and institutional factors and other relevant data assumed to meet the objective of the study were collected from randomly selected farm households in the study district. The Primary data collection process was made in May 2018 using structured questioner which was administered by trained enumerators with the supervision of the researcher. The questionnaire was designed and pre-tested in the field for its validity and content, and to make the overall improvement of the study and in line with the objectives of the study. While secondary data were collected from different published and unpublished sources, such as national planning commission, regional office of agriculture, district economic and finance development offices, district agricultural offices and kebele development agents were consulted to generate relevant data for the study. Besides, average local food price list was collected from trade and industry offices of the study district that show monthly basic food items.

\subsection{Sampling Technique and Sample Size Determination}

Three stage sampling procedure was employed to select respondent farmers. The first stage was stratification of the
District consisting of 25 rural kebeles (excluding urban kebele) in to two agro-ecological zones of which twenty rural kebeles were found in Dega and five kebeles were found in Woyena dega. In the second stage five rural kebeles proportional to the agro-ecological zones were randomly selected in both strata. Implying that four kebeles in Dega and one kebele in Woyena dega were selected. Finally, after identifying the sampling frame which contains the complete fresh list of all households within each selected kebele, respondent farmers were selected randomly in proportion to their total number of households in each kebele. The total number of sample size was determined by simple formula of Yamane [13].

Hence, Yamane formula is given as follows

$$
\mathrm{n}=\frac{N}{1+N(e)^{2}}
$$

where, $\mathrm{n}$ is the sample size, $\mathrm{N}$ is the total population of rural households in the selected kebeles of the district, and $\mathrm{e}$ is level of precision set at 7 percent. Accordingly, the total sample size for this study was 190 households.

\subsection{Methods of Data Analysis}

In order to answer the specified objectives of the study, descriptive analysis, Foster-Greer-Thorbecke (FGT) poverty measures and econometric methods of analysis were 
employed.

Descriptive Analysis: In order to set poverty lines, the cost of basic needs approach (CBN) was used. It comprises a food bundle items that would provide minimum of 2,200 Kcal per person per day, which is the minimum calories required for an adult to maintain an average physical life under normal conditions [14]. Therefore, a household is considered to be living in poverty provided that the per capita daily household consumption expenditure was unable to attain 2,200 kcal. Besides, data on household's annual expenditure on non-food basic needs were included. But expenditure on durable goods were not included in this study. Hence, the sum of expenditure on food consumption and the expenditure on non-food basic needs results the total annual expenditure of the household. Accordingly, the total poverty line was determined.

Hence, Foster-Greer-Thorbecke (FGT) index, measure of poverty can provide us the incidence of poverty (measured by the headcount ratio $\alpha=0$ ), the depth of poverty (measured by poverty gap index $\alpha=1$ ), and the severity of poverty (measured by the squared poverty gap index $\alpha=2$ ).

Mathematically, the FGT index can be computed;

$$
P_{\alpha}=\frac{1}{N} \sum_{i=1}^{n}\left(\frac{z-x i}{z}\right)^{\alpha}
$$

Where, $\alpha=0,1,2$

$\mathrm{P}_{\alpha}$, poverty measure

$\mathrm{Z}$, poverty line

$\mathrm{Xi}$, consumption expenditure of the household per adult equivalent

$\mathrm{N}$, number of sample households

$\mathrm{n}$, number of poor households

$\alpha$, measure of sensitivity of the index to poverty

The second objective of this study was analyzed using poverty statistic in which the property of decomposability by population subgroups and sensitivity to expenditure/income distribution among the poor [15]. Thus, for the ith household below poverty line, the expected time needed to exit poverty if consumption per capita grows at a positive rate $g$ per year is:

$$
t_{g \cong}^{i} \frac{\ln (z)-\ln \left(y_{i}\right)}{g}=\frac{\mathrm{w}}{g}
$$

Where, $\mathrm{y}_{\mathrm{i}}=$ per capita annual consumption expenditure in the $\mathrm{i}^{\text {th }}$ poor household, $\mathrm{g}$ is consumption per capita growth rate, $\mathrm{z}$ is poverty line and $\mathrm{W}$ is Watts index.

If one can estimate the individual poor household exit time, it is not hard to estimate the average exit time of the poor households. It considers the per capita consumption expenditure of the poor households per year given consumption per capita grows at positive rate per year is;

$$
t_{g}^{a v} \approx \frac{\ln (z)-\ln \left(\mu_{p}\right)}{g}=\frac{w}{g}
$$

Where; $\mu_{\mathrm{p}}$ the average per capita consumption expenditure of the poor households (those who are below the poverty line).

Poverty determinants can be analyzed in a number of econometric models. For this particular study, censored Tobit regression model was employed.

Tobit Regression model: It was first developed by Tobin in 1958 and has been widely used by economists for measuring effect of changing explanatory variables on probability of being poor. The Tobit model is a member of censored regression models, which has a latent (dependent) variable that is not observed, whereas the explanatory variable is observable.

Tobit model is an extension of Probit model and it is one of the approaches dealing with the problem of censored data [16]. It is a hybrid of the discrete and continuous dependent variables. When the data are censoring problem, the distribution that applies to the sample data is a mixture of discrete and continuous variable. The use of Tobit model is conceptually preferable to conventional linear regression models because parameter estimates from the former overcome most weaknesses of linear probability models namely: providing estimates which are asymptotically consistent and efficient [17]. In Censored regression model independent variables are known for all observation in the sample but data of dependent variable is observable only in limited boundary (in this case those households who are below poverty line). In addition, Tobit model measures not only the probability of a household being poor but also the intensity or depth of poverty [18].

Therefore, for this particular study Tobit regression model was conceptualized to determine rural households' poverty determinants. The model is chosen because it has an added advantage over other discrete models (logit or probit) in that it measures not only the probability of a household being poor but also the intensity of poverty level.

The Tobit will be specified as the follows;

$$
\begin{gathered}
P_{i}^{*}=\beta X_{i}+e_{i} \\
P_{i}=0 \text { if } P_{i}^{*} \leq 0(\text { i.e } Z<I)
\end{gathered}
$$

Hence, we have censoring at zero,

$$
P_{i}=P_{i}^{*} \text { if } P_{i}^{*}>0(\text { i.e } Z>I)
$$

Therefore, the observed model is

$$
P_{i}=\beta X_{i}+e_{i} \text { if } P_{i}^{*}>0 \text { and } P_{i}^{*}=0 \text { otherwise }
$$

Where $\mathrm{P}_{\mathrm{i}}=$ Limited dependent variable. The dependent variable is poverty level of the respondents. The poor households are represented by poverty depth, while the nonpoor households have zero as their dependent variable.

$\mathrm{P}_{\mathrm{i}}^{*}$ is latent variable that may or may not be directly observable.

$\mathrm{P}_{\mathrm{i}}^{*}$ is observable for poor and unobservable for non-poor.

$x_{\mathrm{i}}=$ explanatory variables, those were supposed to determine poverty (age of household head, household size, sex of household head, TLU, land holding, oxen ownership, non/off-farm income, credit utilization, input utilization, asset ownership, irrigation utilization, cooperative membership etc.) and $\mathrm{e}_{\mathrm{i}}$ is disturbance error.

$\beta_{\mathrm{i}}=$ vector of estimable coefficient parameters.

$\mathrm{I}=$ the mean annual consumption expenditure on food and non-food basic items

$\mathrm{Z}=$ Poverty line

$\mathrm{i}=1,2,3, \ldots \ldots \mathrm{n}$, the number of observations (sample). 
Unlike the case of ordinary least square (OLS) coefficients, it is difficult to interpret the estimated coefficients of the Tobit model as a marginal effect because there are three main conditional expectations of interest. These are; the conditional expectation of the underlying latent variable $\left(\mathrm{y}^{*}\right)$, the conditional expectations of the uncensored observed dependent variable $(y \mid y>0)$ and the conditional expectation of the observed dependent variable (y). Following Greene (1997), [16, 17], the marginal effects of these conditional expectations of the Tobit model, respectively are given as follows;

$$
\begin{gathered}
\frac{\partial E\left(y^{*} / x\right)}{\partial x}=\beta \\
\frac{\partial \operatorname{Pr}\left(y>\frac{0}{x}\right.}{\partial x}=\Phi\left(\frac{x \beta}{\sigma}\right) \frac{\beta}{\sigma} \\
\frac{\partial \mathrm{E}(y / x)}{\partial x}=\beta \Phi\left(\frac{x \beta}{\sigma}\right)
\end{gathered}
$$

Definitions of Variables and Working Hypothesis

Table 1. Summary of the variables included in the study.

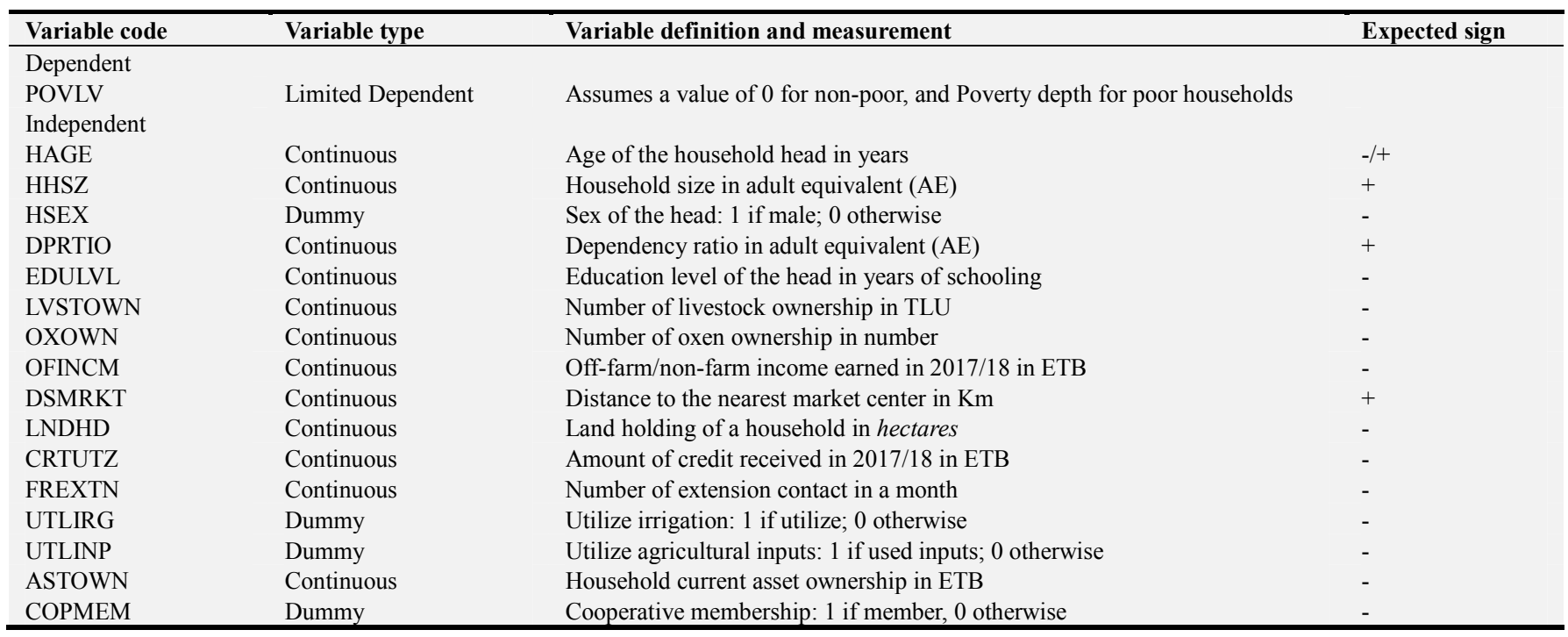

Source: Own definition (2018)

\section{Results and Discussion}

\subsection{Poverty Line Determination}

In order to achieve the objectives of this study constructing poverty line using cost of basic needs (CBN) approach was used. Based on the cost of basic needs approach, first estimate the cost of acquiring enough food for adequate nutrition usually 2,200 kilocalric requirement per person per day, and secondly add the cost of other non-food basic essentials such as clothing, shelter, transport, medical services, schooling, grinding, social and religious expenses, etc. In other words, first determining the food consumption bundle "Food basket" just adequate to meet the required food energy requirements at prevailing market price; and second, adding an allowance for non-food basic needs to food expenditure.

Accordingly, the "Food basket" which constitute seventeen food items either from their stock and or purchase were identified. Then these food items were valued at the annual average local prices of the study district in 2017/18. These consumed food items were converted to kilocalorie and then divided to households in adult equivalent. Therefore, on the nationally predetermined minimum caloric requirement $(2,200 \mathrm{kc})$ for daily activities, the food poverty line in the study area was determined. Subsequently, the food poverty line that gives the minimum daily food caloric requirement was Birr 3232.42 per adult per year as shown in Table 5 below. Hence, the food poverty line that demarcates the poor from the non-poor households was birr 8.85 per day per adult equivalent. Put differently, an adult requires 8.85 Birr per day to attain the minimum $2,200 \mathrm{Kcaloric}$ requirement for his/her daily life.

From the total sample respondents, 83 households were found to be unable to meet the minimum subsistence food requirement whereas 107 households were found to meet their energy requirement. The food poverty line of the study district was below the national average of Birr 3772 in $2015 / 16$. The reason might be low food prices in the study district compared to other parts of the country. Besides, the majority of farmers in the district were producing nonmarketable crops, which further leads them unable to purchase the required food items.

Once the food poverty line is determined it is easy to compute the total poverty line. The food poverty line obtained is translated and incorporated the expenditure required to attain basic non-food needs. Hence, the non-food poverty line can be estimated as the share of the food expenditure to total expenditure of each household in adult equivalent on a constant and the $\log$ of the ratio of total expenditure to food poverty line [19]. Accordingly, the food 
shares of households that had failed to attain the food poverty line was found to be 75.14 percent whereas the share of nonfood was 24.86 percent. Subsequently, the non-food expenditure in the study area was Birr 1069.45 per adult per year and, therefore, gives the total poverty line of Birr 4301.85 per adult per year. In other words, the absolute poverty line (the sum of food poverty line and non-food poverty line) that demarcates the poor households from the non-poor was found to be Birr 4301.85. Those households whose mean annual consumption expenditure falls below Birr 4301.85 per adult were counted as poor and those households whose mean annual consumption expenditure above this "cut-off" point were counted as non-poor. In other words, an adult requires a subsistence consumption expenditure of Birr 359 per month at 2017/18 crop prices in the study area.

According to national planning commission of Ethiopia [20], the national annual consumption expenditure poverty line was Birr 7184. Compared to this figure, the study area annual consumption expenditure is low. The probable justification might be, the ability of farmers, in the study area, to spend on non-food items is weak as they are short of cash and usually hardly fulfill their non-food items.

\subsection{Poverty Measures and Its Status}

The three well known group of poverty measures namely head count ratio (incidence of poverty), poverty gap (extent of poverty) and poverty gap squared (severity of poverty) were analyzed using Foster-Greer-Thorbeke equation (13). Based on the poverty line determined above, the FGT class of poverty indices were found to be $0.44,0.09$ and 0.02 for head count, poverty gap and poverty severity respectively.

Table 2. Poverty measure of sample households.

\begin{tabular}{ll}
\hline Poverty index & Values \\
\hline Poverty head count index & 0.44 \\
Poverty gap index & 0.09 \\
Poverty severity index & 0.02 \\
\hline
\end{tabular}

Source: own survey computation (2018)

Poverty head count index: The headcount index measures the proportion of the sample population that is counted as being poor. Table 6 above revealed that the absolute head count index of the sampled population showed that 44 percent of households were considered as poor or 44 percent of sampled populations were unable to fulfill the predetermined minimum consumption requirement. This figure is considerably higher than the national and regional figure reported by the government of Ethiopia [20]. Hence, the study district is one of the highest poverty incidence registered in the region. Poverty head count does not capture how the poor are and does not change if people below poverty line become poorer.

Poverty gap index: This measures the average proportionate poverty gap of consumption expenditure of the population where the non-poor households have zero poverty gaps. It tells us the extent to which an individual is found below the poverty line. Accordingly, the mean aggregate consumption shortfall relative to the poverty line across the whole population is found to be 0.09 . In other words, the poor households require an additional 9 percent of the present consumption expenditure to attain their minimum basic needs. Although the poverty gap index is the mean of the gaps between the welfare of the poor and poverty line, it does not capture the consumption inequality among the poor households.

Poverty severity: This index measures not only the distance separating the poor households from the poverty line but also considering the inequality among the poor. Thus higher weight is placed on those households further away from the poverty line. The severity index for this particular study was 0.02 implying that there exists 2 percent consumption inequality among sampled poor household in the study area. The figure is consistent with the Amhara National Regional State severity of 2.4 percent in 2015/16.

\subsection{Consumption Expenditure}

The survey result showed that the overall annual mean consumption expenditure per adult equivalent for the sample population was Birr 4624.2 per year with standard deviation of 1512.8. As shown in table 3 below, the mean consumption expenditure of poor and non-poor groups of households were Birr 3355.1 and 5629.8 with standard deviation 1285.4 and 446.8 respectively. Statistically there was significant mean difference between poor and non-poor sample population at 1percent significance level. Besides, annual mean consumption expenditure on food and non-food sample population was Birr 3810.8 and 2092.9 with standard deviation of 1463.7 and 443.6. There was statistically significant mean difference between the poor and non-poor sample households in terms of food and non-food expenditure per annum per adult equivalent at 1 percent significance level.

Table 3. Total expenditure and food expenditure of sampled households per year in Birr

\begin{tabular}{llllll}
\hline \multirow{2}{*}{ Expenditure } & \multicolumn{2}{l}{ Poor $(\mathbf{N}=\mathbf{8 4})$} & \multicolumn{2}{l}{ Non-poor $(\mathbf{N}=106)$} & t-value \\
\cline { 2 - 6 } & Mean & St. Dev & Mean & St. Dev & \\
\hline Total & 3355.1 & 446.7 & 5629.8 & 1285.4 & $15.48^{* * *}$ \\
Food & 2579.4 & 543.9 & 4786.6 & 1203.4 & $15.58^{* * *}$ \\
Non-food & 1781 & 293.3 & 2339.5 & 383.9 & $11.01 * * *$ \\
\hline
\end{tabular}

Source: Own survey computation (2018)

*** significant at $1 \%, 5 \%$ and $10 \%$ significance level

\subsection{Association of Livelihood Capitals of Households with Poverty}

In this section different livelihood capital which are assumed to influence the rural farmers were analyzed. It includes human capitals, physical capitals, finical capitals, natural capitals and other institutional aspects were discussed accordingly.

\subsubsection{Human Capital}

Human capital represent once skill, knowledge, ability, 
education, good health which helps an individual to increase his/her productivity and to pursue different livelihood strategies. In this study human capital included sex, education, family size, extension contact, age and dependency ratio. Accordingly, the total size of sample household members was 1186 out of this sample household members 629 (53 percent) were male and 557 (47 percent) were female. Of the total sample household members 16 percent were household heads.

Based on the survey result showed in table 4 below, from the total sample households 87 percent and 13 percent were male and female headed households respectively. The average household size in AE was 5.1 per household with standard deviation of 1.7. The figure exceeds the national average of 4.2 persons per household. Educational attainment of sampled households or literacy rate was 1.6 years of schooling on average with in the rage of illiterate and eleventh grade maximum. Besides, 57 percent of sampled households were unable to read and write. The mean age of sample household head was 47.8 years with standard deviation of 10.23 . The youngest household head was twenty and the oldest was eighty years. The average dependency ratio was 0.76 with minimum and maximum of zero and 3.5 respectively. Extension visit made by household head or contact on average was 3.3 days per month.
Analyzing human capital based on poverty status can give us more sound information, educational attainment of household head showed statistically significant mean difference between the poor and non-poor sampled households. The average educational attainment of the head of the poor households was 0.7 years with standard deviation of 1.7 whereas the non-poor household heads were 2.4 years with standard deviation of 3 with statistical mean difference at 1 percent significant level. The negative value of t-test indicted that education attainment of the household head and the poverty status was negatively correlated. The average household size of poor households in AE was 5.3 per household with standard deviation of 1.6 and that of nonpoor households was 4.9 with standard deviation of 1.7.

The average age of poor households was 48.5 years with standard deviation of 9.02 whereas the non-poor households were 47.30 years with standard deviation of 11.12 . There was no significant mean difference between the two groups in terms of the age of the head of the household. The dependency ratio which indicates ratio of non-active members to that of active household members between the poor and non-poor was 0.8 and 0.73 with no statistical mean difference. Extension visit or contact made by a household between the poor and non-poor groups was 3.3 and 3.4 days per month respectively with no significant mean difference.

Table 4. Human capitals with poverty level.

\begin{tabular}{|c|c|c|c|c|c|c|c|}
\hline \multirow{2}{*}{ Human capital } & \multicolumn{2}{|c|}{ Poor $(N=84)$} & \multicolumn{2}{|c|}{ Non-poor $(\mathrm{N}=106)$} & \multicolumn{2}{|c|}{ Total $(\mathrm{N}=190)$} & \multirow{2}{*}{ t-value } \\
\hline & Mean & St. Dev & Mean & St. Dev & Mean & St. Dev & \\
\hline Age & 48.5 & 9.1 & 47.3 & 11.1 & 47.8 & 10.23 & -0.8 \\
\hline Household size & 5.3 & 1.6 & 4.9 & 1.7 & 5.1 & 1.71 & -1.08 \\
\hline Education level & .7 & 1.7 & 2.4 & 3.0 & 1.3 & 2.63 & $-4.56 * * *$ \\
\hline Dependency ratio & 0.8 & 0.6 & 0.7 & 0.6 & 0.7 & 0.63 & -0.78 \\
\hline Extension contact & 3.3 & 1.7 & 3.4 & 1.8 & 3.4 & 1.77 & -0.06 \\
\hline
\end{tabular}

Source: Own survey result (2018)

*** significant at $1 \%$ significance level

Sex of the head of the household is one of human capital in which it influences poverty. From the total sampled household population 87.9 percent of the respondents were male headed whereas 12.1 percent were female headed households. The non-poor male headed households were 80 percent and that of female headed were 20 percent. Out of the total female headed respondents the majority (67 percent) were poor. Correlation test using Person chi-square does not show any significant mean difference between the poor and non-poor groups of the respondents in terms of sex of the household head.

\subsubsection{Physical Capital}

In this study housing, livestock ownership, oxen ownership, access to farm inputs, distance to nearest market place in kilometer and input utilization were considered as physical capitals. The housing type of sample households was either corrugated iron sheet, grass roofed or both types. Among the sampled respondent households 68.9 percent, 5.8 percent and 25 percent were possessed corrugated iron roof, grass roofed and both types respectively. Majority of farmers in both poor and non-poor groups live in corrugated iron sheet homes with 65.3 percent and 80 percent, respectively.

Hence, large number of livestock unit helps the rural farmers to fulfill their food and non-food requirements. As shown in table 5 below, the average number of livestock ownership measured in TLU and oxen size per household were 3.3 and 0.9 respectively with standard deviation of 1.83 and 0.84. Moreover, maximum and minimum livestock and oxen holding were 10.1 and 3.3 respectively.

Proximity to nearest market had significant influence on poverty status of the household. In the study area the average distance that sampled households reach the nearest market is $7.2 \mathrm{~km}$ with the longest distance of $24 \mathrm{~km}$ and the smallest of $0.5 \mathrm{~km}$ with standard deviation of $4.6 \mathrm{~km}$. Input utilization is also one important factor in rural farmers in which it helps to increase production and productivity. Input includes improved seed, organic and inorganic fertilizer, chemicals like pesticides and herbicides, and different agronomic practices. Following this, 62 percent of the sampled respondents were utilized at least one agricultural input notably inorganic fertilizer in 2017/18 production season.

Physical capital might have different compositions in poor 
and non-poor sampled household groups. As indicated in table 5 below, the average number of oxen owned by the poor and non-poor groups of sampled households was 0.5 and 1.3 respectively. There is statistically significant mean difference in oxen ownership between poor and non-poor sampled households at 1 percent probability level. Here, nearly 43 percent of the respondents in the study area did not have any oxen in the survey year. The average livestock ownership in TLU in the study area was 2.7 units for the poor and 3.8 units for non-poor households with standard deviation of 1.4 and 2.1 respectively. There was highly statistically significant mean difference observed between poor and non-poor households in terms of TLU at 1 percent probability level.
Regarding to proximity to the nearest market center, the average distance of the poor farmers was $8.04 \mathrm{~km}$ with standard deviation 4.59 whereas the non-poor households average distance was $6.51 \mathrm{~km}$. The result showed that poor households are living far away from the market place than the non-poor households. Besides, significant mean difference was observed between poor and non-poor groups in terms of nearest market center at 5 percent probability level. Moreover, among input users 38 percent and 81 percent of poor and non-poor sample households utilized at least one of the agricultural input. Input utilization showed significant mean difference between the poor and non-poor households at 5 percent significance level.

Table 5. Physical capital of sample households with poverty status.

\begin{tabular}{|c|c|c|c|c|c|c|c|}
\hline \multirow{2}{*}{ Physical capital } & \multicolumn{2}{|c|}{$\operatorname{Poor}(\mathrm{N}=84)$} & \multicolumn{2}{|c|}{ Non-poor $(\mathrm{N}=106)$} & \multicolumn{2}{|c|}{ Total $(N=190)$} & \multirow{2}{*}{ t-value, chi2 } \\
\hline & Mean & St. Dev & Mean & St. Dev & Mean & St. Dev & \\
\hline Number of oxen & 0.5 & 0.7 & 1.3 & 0.96 & 0.9 & 0.84 & $6.54 * * *$ \\
\hline Livestock size (TLU) & 2.7 & 1.36 & 3.8 & 3.03 & 3.3 & 1.83 & $4.21 * * *$ \\
\hline Nearest market (Km) & 8.1 & 4.72 & 6.5 & 4.38 & 7.2 & 4.60 & $-2.28 * *$ \\
\hline Input utilization $(1=$ yes $) \%$ & 0.38 & & 0.8 & & 0.6 & & $36.91 * *$ \\
\hline
\end{tabular}

Source: Own survey result (2018)

$* * *, * *$ and $*$ significant at $1 \%, 5 \%$ and $10 \%$ significance level respectively

\subsubsection{Financial Capitals}

Financial capital comprises cash and non-cash availability and regular and non-regular inflows of money enabling people to adopt different livelihood strategies and hence achieve their livelihood strategies [21]. For this particular study the financial capitals include credit utilization, asset ownership, on farm income and off/non-farm income received in 2017/18 production year. As shown in table 6 below, the annual average credit received by respondent farmers were Birr 4408 with minimum. The maximum credit taken by respondent households was Birr 20,500. The main and most accessible source of credit is from Amhara Credit and Saving Institute (ACSI). Besides, from the whole sample population 63 percent were used credit either for input purchase or household food consumption. The average annual income obtained from on-farm income and off/nonfarm income was Birr 6294.8 and Birr 6896 respectively.

There is highly statistically significant mean difference between the two groups were observed at 1 percent probability level. The mean annual current asset value of poor rural farmers was Birr 750 with standard deviation of 612 and their counter non-poor was Birr 1500 with standard deviation of 1304 . Besides, there is highly statistically significant mean difference between poor and non-poor sample households at 1 percent probability level. Similarly, annual earnings obtained from sale of agricultural goods either crop yield or livestock and livestock products was Birr 3,783 while their counter non poor groups was Birr 6225 with highly statistically significant mean difference at 1 percent probability level.

Table 6. Financial capitals with poverty status (ETB per annum).

\begin{tabular}{|c|c|c|c|c|c|c|c|}
\hline \multirow{2}{*}{ Financial capitals } & \multicolumn{2}{|c|}{$\operatorname{Poor}(\mathrm{N}=84)$} & \multicolumn{2}{|c|}{ Non-poor $(N=106)$} & \multicolumn{2}{|c|}{ Total $(N=190)$} & \multirow{2}{*}{ t-value } \\
\hline & Mean & St. Dev & Mean & St. Dev & Mean & St. Dev & \\
\hline Credit Received & 3,148 & 2886 & 5407 & 5056 & 4408 & 4370 & $3.64 * * *$ \\
\hline Asset Value & 750 & 612 & 1,500 & 1,304 & 1172 & 1116 & $4.88 * * *$ \\
\hline On-farm income & 3,783 & 5,386 & 6,225 & 6,762 & 6294 & 5146 & $2.67 * * *$ \\
\hline Off/on-farm income & 5,281 & 4,450 & 8,176 & 8,596 & 6896 & 7199 & $2.8 * * *$ \\
\hline
\end{tabular}

Source: Own survey result (2018), ***significant at $1 \%$ significance level respectively

\subsubsection{Natural Capital}

Natural capital is the quality and quantity of natural and environmental stock from which resources flows and services are useful for livelihood of rural farmers [21]. This study includes irrigation use and land holding as its natural capital. Accordingly, the average land holding in the study area was 1.04ha with a maximum area of 4 ha, and 4.7 percent of sampled households did not have any type of land in the survey season. The other important natural capital included in this study was irrigation use. In the study area only 22 percent of the respondents have access and use of irrigation water implying that the majority were entirely depend on rain fed agriculture. Unavailability of irrigation water and shortage of land was identified as the major constraint of the irrigation sector in the study area. 
Regarding to the poverty status of sampled households the average land holding of the poor household was 1.03 ha with standard deviation of 0.55 where as its counter non-poor was 1.04ha with standard deviation of 0.62 . Poverty status and land holding did not show any significant differences between poor and non-poor households. Besides, nearly 14 percent of poor farmers had access and irrigated their land while 28 percent of non-poor farmers were also irrigated their land with statistical mean difference at 5 percent probability level.

\subsubsection{Other Institutional Capital or Characteristics}

Institutional capitals can play significant impact in any society. It is to mean that institutions guide or arrange an individual or community to make life easier. The main motive of any government is to create conducive institutional arrangements that help economic agents can operate at their lowest transaction costs. In this study institutional capitals or services included were human health services, veterinary services and cooperative access. Following this, the majority of (79 percent) of sample population had access to veterinary services.

Human health coverage in the study area was 72.6 percent. The human health service delivers mostly for women and babies on disease prevention and free delivery of drugs usually (contraceptives, antibiotics of TB, etc). There was significant mean difference observed in terms of human health service between poor and non-poor groups. There was no significant association between the poverty status and cooperative membership in the study area. Usually most primary cooperatives in the study area provide inorganic fertilizer up on credit or cash.

\subsection{Time Needed to Exit Poverty}

Any developing country's ultimate target or goal is eradicating poverty and enhancing the wellbeing of its citizens. To do so, achieving sustained economic growth could be considered as great importance. Despite the importance of economic growth, it will generally take more than just growth to rapidly improve the lives of the poor. Estimating expected time to exit poverty for those who are below the poverty line given positive economic growth rate is increasingly becoming popular these days for policy issues and poverty reduction interventions [15].

Thus, targeted programs are needed to deliver benefits to the poor for instance in the form of improvements in their human and physical assets or through interventions that improve the returns they get from assets [22]. Therefore, the concept of average time needed to exit poverty is central to lift majority of the poor households from poverty.

For policy makers, the average exit time for the poor households might sound more than the average exit time of the whole sample households. If the poverty exit time for the whole sample population is estimated, the conclusion might lead the policy makers neglecting to remember that many people are already poor. Hence, based on the national bank of Ethiopia, the average national real gross domestic product (RGDP) from 2005/06 up to 2009/10 (EFY) was used to estimate poverty exit time. The computed average RGDP for the five year was 7.7 percent.

Therefore, the estimated average time needed for poor sample households to exit poverty would be 3.35 years as shown in table 7 . The is to mean that it requires 3.35 years so that the poor households to move out of poverty or at least bring them to the pre-determined poverty line given average per capita consumption expenditure of the poor households was minimum of Birr 3355 per annum and GDP per capita continue to register at least 7.7 percent per year (Appendixes 4). Besides, the average time required to bring the average poor household to the poverty line was 3.22 year. The additional exit time across the whole poor sample households and average poor sample household is 0.13 years. This is due to low consumption inequality amongst the poor households the additional exit time ( 0.13 year) looks insignificant. If the analysis was made for the whole sample population, the poor households in the study area were already non-poor before three months (back to the survey year). It is therefore, important concept for identifying economic opportunities and challenges that poor people are benefiting and suffering. Besides, respective authorities can make use of necessary policy or strategy adjustments based on the estimated exit time. Previous findings showed that sustained economic growth can have a potential to reduce poverty. Research conducted by in Gozamen district of Amhara National Regional State found that the average exit time for the average poor household was four years [23].

Even though growth is unlikely to be uniform or constant for years across households or regions, the average exit time provides a simple and quick way for poverty alleviation through growth. Therefore, achieving broad based economic growth is important policy agenda, and developing analytical tools to consider poverty and economic growth jointly.

Table 7. Average time needed to exit poverty at $7.7 \%$ growth rate of RGDP of the country.

\begin{tabular}{ll}
\hline Poverty measure & Estimated Value \\
\hline Average exit time of poverty for the average poor sample household & 3.22 years \\
Average exit time of poverty for poor sample households & 3.35 year \\
Additional year due to inequality amongst the poor & 0.13 year \\
Average GDP growth rate of the country* & $7.7 \%$ \\
Poverty line for the sampled households & Birr 4301.85 \\
Average per capita consumption expenditure of the poor sampled households & Birr 3355 \\
\hline
\end{tabular}

Source: Own survey result (2018), *Average five year RGDP (EFY2005/06-2009/10) 


\subsection{Econometric Model Results}

To ascertain the effects of the explanatory variables related to poverty level of the households, Tobit regression model was employed. The dependent variable is the poverty level of the households, where the poor households were represented by poverty depth whereas non-poor households have zero as their dependent variable.

Accordingly, sixteen explanatory variables were included for Tobit regression model that were assumed to influence the poverty level in the study area. Seven variables were found to be statistically significantly influenced poverty level of the households in the study area. The possible explanations for each significant explanatory variable are briefly discussed below.

Educational level of household head (EDUCLV): Education is considered as one of the basic human capital that help individuals move out of poverty. According to this study, educational attainment of the household head found to have negative and significant influence on poverty at 5 percent significance level. The result implies that households who have household heads with relatively better education are less likely to be poor than those headed by uneducated (illiterate) household heads. The marginal effects, keeping other variables constant, showed that as the household head education level increases by one grade the probability of a household being poor would decrease by 4.7 percent while it decreases the intensity or expected value of poverty by 0.7 percent and 0.9 percent for the poor households and for the whole observation, respectively. This might be the fact that educated household heads have in a better position to adopt improved and best bet agricultural technologies than less educated or uneducated ones. This further raises the productivity, efficiency and income of the educated heads with subsequent improvement of their living condition. The result is similar with the previous findings of Tasew and Tekie, [25] and Adane [24].

Oxen Ownership (OXOWN): As expected, the number of oxen ownership was found to negatively and significantly influenced poverty level at less than 1 percent significance level. The negative sign indicates that households with large number of oxen have less likely to be poor compared to households with less number of oxen holding. The negative sign indicates that households with higher number of oxen are less likely to be poor than households with few or no oxen. The marginal effects of oxen ownership revealed that the probability of a household being poor tends to decrease by 19.2 percent for every addition of ox possessed by the household, whereas it decreases the intensity of poverty by 2.7 percent and 3.6 percent for the poor households and the whole sample observation, respectively. The possible reason could be; rural households are largely dependent on oxen for draught purpose there by plowing either their land or may enter for sharecropping arrangements with other households who have cultivable land holding but no oxen. Accordingly, those who have oxen can produce more food and income for his family. The result is consistent with Ayalneh and Kornard
[26].

Number of Livestock Ownership (TLU): Number of livestock ownership in TLU in rural areas is considered as one of the basic livelihood assets. As hypothesized, number of livestock owned measured in TLU was found to negatively and significantly contribute to the level of poverty at 10 percent significance level. Keeping other variables constant, the marginal effect of TLU indicates that increasing the number of livestock by one TLU the probability of a household being poor decreases by 4.4 percent while it decreases the intensity of poverty level by 0.7 and 0.9 percent for the poor households and for the whole observation, respectively. The result revealed that livestock do have an important asset for the majority of rural households. It served as an immediate source of income by selling the lives and/or its product to fulfill food and non-food requirements of the household. The finding is similar with that of Degye [27].

Household size (HHSZ): As expected, household size was found to significant and positively related with poverty level at 10 percent significance level. The positive relationship shows that as household size increases the probability of a household being poor would increase. Considering the marginal effect, as the member of household increases by one adult equivalent the probability of a household being poor would increase by 3.8 percent while it increases the intensity of poverty by 0.5 and 0.7 percent for the poor households and for the whole observation of the study, respectively. The possible reasons might be when most members of the households are dependents due to existing high rate of unemployment and less job opportunities in rural areas, an additional household member shares the limited resource that lead the household to become poor. This result has been supported with the findings of Ayalneh and Abebaw [28].

Credit Utilization (CRUTL): As expected, credit utilization of a household was found to significant and negatively influenced poverty at less than 1 percent significance level. The negative relationship shows that the probability of a household being poor decreases as a household receives credit. The marginal effect showed that an increase in the amount of credit by one thousand ET birr, the probability of a household being poor decreases by 3.2 percent while it decreases the intensity of poverty by 0.4 percent and 0.6 percent for the poor ones and for the whole sample observation of the study, respectively. The possible explanation is that credit plays vital role when cash constraint happened either to finance farm input and/or purchase other immediate food and non-food basic requirements. Besides, credit helps rural farmers to involve in long term income generating activities that ultimately help them move out of poverty trap. The result is consistent with the findings with that of Girma [29].

Asset Ownership (ASTOWN): As expected, value of asset ownership available in the household was significantly and negatively related with poverty level at 10 percent significant level. Considering the marginal effects, as the value of household's current asset increases by one thousand Birr the probability of a household being poor would decrease by 
10.1 percent, while it decreases the intensity of poverty by 1.4 percent and 1.9 percent for the poor households and the whole sample observation, respectively. The possible explanation could be households having larger asset have the capacity to withstand economic shocks and income shortfalls. Accordingly, ownership of household assets helps farmers as a fallback strategy against shocks because some of the assets could be sold to support households cash requirement. The finding is similar with Girma [29] and Asgwoa [30].

Input Utilization (UTLINP): The study result suggests that households who used improved agricultural input was found to significant and negatively influenced poverty at less than 1 percent significant level. The negative relationship indicates, a household who used improved agricultural input are less likely to be poor than those who did not. The marginal effects showed that those households who used improved agricultural input, the probability of being poor would decrease by 32.1 percent, while it decreases the intensity of poverty by 4.5 percent and 6 percent for the poor ones and the whole observation of the study, respectively. The result agrees with the previous findings of Eshetu [31].

\section{Summary, Conclusion and Recommendations}

\subsection{Summary}

This study was designed to investigates the household level poverty situation and determinant factors of poverty in rural areas of Banja district Amhara National Regional State, Ethiopia. In order to investigate poverty situation of the study area, the researcher employed the cost of basic needs approach. Accordingly, the total poverty line that demarcates poor households from non-poor households was Birr 4301 per adult per year. The food poverty line and non-food poverty line was Birr 3232 and 1069 respectively per adult per year. FGT class of poverty measure were $0.44,0.09$ and 0.02 for poverty head count, poverty gap and poverty severity, respectively.

Based on the survey result, an attempt was made to describe whether there exists significant mean difference was observed between the poor and non-poor sample respondents regarding to annual mean consumption expenditures. Accordingly, there is significant mean difference between poor and non-poor sample households in terms of annual total consumption expenditure, annual food expenditure and non-food expenditure per adult per year.

Significant mean difference was observed between poor and non-poor sample households in terms of educational attainment of the household head, oxen ownership, TLU, input utilization, asset ownership, on/off farm income, distance to the nearest market and credit utilization. Poor households have larger family size in AE than counter nonpoor households. Besides, poor household head had low level of educational attainment than their counter non-poor household heads.

Estimating the average time needed to exit the poor households from poverty in the study area was estimated to be 3.35 years. In other words, it takes 3.35 years to push the poor households in to poverty line given GDP per capita continues to grow at minimum rate of 7.7 percent per annum. Besides, the average exit time for the average poor farmer was 3.23 years.

Econometric results of Tobit regression model employed sixteen explanatory variables. Accordingly, seven variables were found to significantly influence rural poverty in the study area. These were livestock ownership in TLU, number of oxen ownership, total family size in $\mathrm{AE}$, educational attainment of the household head, input utilization, value of asset ownership and credit utilization significantly influenced poverty.

\subsection{Conclusion and Policy Recommendations}

Based on the findings of this study the following conclusions were made. The proportion of people living below poverty line still remains higher compared to the national and regional rural head count index of 25.6 percent and 28.8 percent, respectively. The result revealed that the average poverty exit time by assuming sustained positive economic growth can lift the poor farmers in nearly three and half years. To do so pro-poor and area specific policy intervention given the consumption pattern of the poor households help them move out of poverty trap. Therefore, sustainable economic growth at the national and regional level is needed so that considerable number of households will be non-poor in the estimated time period. Educational attainment of the household head, livestock ownership, family size, input utilization, asset ownership and credit utilization was found to be an important poverty determinant.

Household size which is an important component of demographic character showed positive contribution for rural poverty. This has direct implication on the income and resources available in the household which worsen the poverty situation of the household. Therefore, family planning through awareness creation and integrated health programs, creating job opportunities for the rural households may lead to acceptable number of children. Livestock have great importance for the majority of households in rural areas. Hence, the livestock sector should be strengthened through the provision of veterinary services and feed supply. Besides, intervention projects that enhance the livestock sector like dairy cow credit, sheep credit and fattening credit need to be supported with the necessary husbandry skill and knowledge.

Educational attainment of the household head was highly related with rural poverty in the study district. The relevant authorities should develop educational program through promoting and expanding of schools in the nearby rural villages as well as strengthen adult education would improve the living standard of the rural poor households.

Utilization of improved agricultural input remarkably improve production and productivity there by increase household income. Therefore, access and provision of improved agricultural input, best bet farming technology and management practices would help the farmers to 
increase production and productivity. Another important poverty determinant in the study area was asset ownership. Accordingly, relevant government authorities or development actors have to design and implement rural household asset building program that enhance the production and productivity of farmers and there by improve their lives.

The last but not the least important poverty determinant in the study area was credit service. Credit can create an opportunity to be involved in economic activity that generates revenue for the rural households. It also supports farm households in solving cash constraints to either to buy food for family or to buy farm input. Thus, government bodies, non-governmental organizations and other relevant authorities shall focus on enhancing and expanding rural credit services for poor rural households at minimum possible transaction and/or collateral cost.

\section{Acknowledgements}

The authors express special thanks to African economic Research Consortium, AERC and Ethiopian Institute of agricultural Research (EIAR) for my research funding. The respondents, data collectors and comments from anonymous reviewers of this study are gratefully acknowledged. However, the usual disclaimer applies: The views expressed in this paper are those of the authors based on field data and should not be attributed to any of the funding organization.

\section{Appendix}

Table 8. Tobit model regression estimates and marginal effects of poverty determinants.

\begin{tabular}{|c|c|c|c|c|c|}
\hline \multirow{3}{*}{ Independent Variables } & \multirow{3}{*}{ Coefficient } & \multirow{3}{*}{ Std. Err } & \multicolumn{3}{|c|}{ Marginal Effects } \\
\hline & & & $\partial \mathrm{E}\left(P^{*} / x\right)$ & $\partial \mathrm{P}(y>0 / x)$ & $\partial E(P / x)$ \\
\hline & & & $\partial x$ & $\partial x$ & $\partial x$ \\
\hline Number of livestock owned (TLU) & $-0.020 *$ & 0.011 & -0.047 & -0.007 & -0.009 \\
\hline Number of oxen own & $-0.081^{* * *}$ & 0.021 & -0.192 & -0.027 & -0.036 \\
\hline Household size (Adult Equivalent) & $0.016^{*}$ & 0.008 & 0.038 & 0.005 & 0.007 \\
\hline Age of the household head & 0.003 & 0.002 & 0.007 & 0.001 & 0.001 \\
\hline Sex of household head & 0.053 & 0.056 & 0.127 & 0.018 & 0.024 \\
\hline Distance from the nearest market & 0.002 & 0.004 & 0.004 & 0.001 & 0.001 \\
\hline Land size owned (ha) & 0.006 & 0.032 & 0.014 & 0.002 & 0.003 \\
\hline Frequency of extension contact & 0.003 & 0.009 & 0.007 & 0.001 & 0.001 \\
\hline Utilization of irrigation & 0.021 & 0.044 & 0.049 & 0.007 & 0.009 \\
\hline Utilization of input & $-0.014^{* * *}$ & 0.034 & -0.321 & -0.045 & -0.059 \\
\hline Value of asset owned (ETB) & $-0.043^{*}$ & 0.025 & -0.101 & -0.014 & -0.060 \\
\hline Dependency ratio & 0.032 & 0.028 & 0.077 & 0.011 & 0.014 \\
\hline Non/off-farm income (ETB) & -0.004 & 0.005 & -0.009 & -0.001 & -0.002 \\
\hline Cooperative membership & 0.009 & 0.034 & & & \\
\hline Constant & 0.012 & 0.118 & 0.023 & 0.003 & 0.004 \\
\hline se & 0.167 & 0.014 & & & \\
\hline
\end{tabular}

Source: Own survey result $(2018), * * *, * * \& *$ significance level at $1 \%, 5 \% \& 10 \%$ respectively.

New York, USA.

\section{References}

[1] WB (World Bank). 2007. World Development Report, World Bank, Washington D. C, USA.

[2] FAO (Food and Agricultural Organization). 2015. The State of Food and Agriculture: Social Protection and Agriculture; Breaking the cycle of Rural poverty. Rome, Italy.

[3] WB (World Bank). 2015. Policy Research Working Paper, Washington D. C. USA.

[4] IFAD (International Fund for Agricultural Development). 2011. Rural Poverty Report: New Realities, New Challenges, New Opportunities for Tomorrow's Generation.

[5] Teshome Kebede and Sharma, M. K. 2014. Determinants of Poverty in Ethiopia. Ethiopia Journal of Economics, 13 (1): $114-130$.

[6] UNDP (United Nations Development Program). 2016. Human Development Report. Human Development for everyone,

[7] Husmann, C. 2016. Marginality as a Root Cause of Poverty: Identifying Marginality Hotspots in Ethiopia. World Development, 78 (C): 420-435.

[8] Ahmed Mohamed. 2013. Determinants of Poverty in Rural Ethiopia: A Household Level Analysis. MSC Thesis, Lund University, Lund, Sweden.

[9] WB (World Bank). 2016. Priorities for Ending Extreme Poverty and Promoting Shared Facility: Systemic Country Diagnostic. World Bank, Washington D. C, USA

[10] NBE (National Bank of Ethiopia). 2017. Annual Report, Addis Ababa, Ethiopia.

[11] CSA (Central Statistics Authority). 2007. Intercensal Population Survey, Addis Ababa, Ethiopia.

[12] Banja district agricultural offices, Unpublished.

[13] Yamane, T. 1967. Statistics, An Introductory Analysis, 2nd Edition. New York. 
[14] EHNRI (Ethiopian Health and Nutrition Research Institute), 2000. Food Composition Table for Use in Ethiopia. Addis Ababa. Ethiopia

[15] Morduch, J. 1998. Poverty, Economic Growth, and Average Exit Time. Economics Letters, 59 (3): 385-390.

[16] Johnston, J. and Dandiro, J. 1997. Econometrics Methods, fourth Edition, New York: McGraw Hill Companies, Inc.

[17] McDonald, J. and Moffitt, R. 1980. The Use of Tobit Analysis. The Review of Economic and Statistics, 62 (2): 318 -321.

[18] Tobin, J. 1958. Estimation of Relationships for Limited Dependent Variables, Econometrcia 26: 24-36.

[19] Ravallion, M. 1992. Poverty Comparisons: A Guide to Concepts and Methods. Living Standard Measurement Study. Working Paper, No, 88. Washington, D. C, USA.

[20] NPC (National Planning Commision). 2017. Ethiopia's Progress Towards Eradicting Poverty: An intrim Report on 2015/16 Poverty Analysis Study. Addis Ababa, Ethiopia.

[21] Scoones, I. 1998. Sustainable Rural Livelihoods: A Framework for Analysis. International Development Studies Working Paper.

[22] WBI (World Bank Institute). 2005. Introduction to Poverty Analysis: Poverty Manual, All, JH Revision.

[23] Tsegaye Molla, 2014. Analysis of Rural Poverty and Exit Time: The Case of Gozamen District of East Gojiam Zone, Ethiopia. Journal of Economics and Development, 5 (27): 310-320.

[24] Adane Nabso. 2002. Magnitude and Determinants of Rural
Household Poverty in Central Ethiopia: The case of Berehe Aleltu District. M. Sc Thesis, Haramya University, Haramaya, Ethiopia

[25] Tassew Woldehanna and Tekie Alemu. 2002. Profiles and Determinants of Poverty. Paper Presented at an International Seminar of Development Strategies for Less Favored Areas. Wageningen, Netherlands.

[26] Ayalneh Bogale, Konard, H. and Benedikt, K. 2005. Determinants of Poverty in Rural Ethiopia. Quarterly Journal of International Agriculture, 44 (44): 101-120.

[27] Degye Goshu. 2013. The Dynamics of Poverty and Vulnerability in Rural Ethiopia. Ethiopian Journal of Economics, 22 (2): 1-20.

[28] Ayalneh Bogale and Abebaw Shemles. 2009. Household Level Determinants of Food Insecurity in Rural Areas of Dire Dawa, Eastern Ethiopia. African Journal of Food, Agriculture, Nutrition and Development, 9 (9): 1914-1926.

[29] Girma Gezimu. 2012. Determinants of Food Insecurity Among Households in Addis Ababa City, Ethiopia. Journal of Interdisciplinary Description of Complex Systems, 10 (2): 159-173.

[30] Asogwa, B., Ummeh, J. and Okwoche, V. 2012. Estimating the Determinants of Poverty Depth among the Peri-Urban Farmers in Nigeria. Current Research Journal of Social Sciences, 4 (3): 201-206.

[31] Eshetu Sied and Adam Bekele. 2011. Determinants of Farm Household Poverty: The Case of Lay Gaint District, South Gonder Zone, Amhara Regional State. M. Sc Thesis, Haramaya University, Haramaya, Ethiopia. 